\title{
ESTIMAREA COMPONENȚEI FEROMONULUI SEXUAL ȘI DETERMINAREA CICLULUI DE DEZVOLTARE SEZONIERĂ A SPECIEI HËIOTHIS ARMIGERA
}

Nastas T., Elisovețcaia D., Cheptinari V., Rusu I., Odobescu V. Institutul de Genetică, Fiziologie și Protecție a Plantelor, Chișinău, Republica Moldova E-mail: tudor_nastas@mail.ru

Abstract: The antennae reaction of the males Heliothis armigera was estimated by means of the electroantenographic apparatus to the components obtained from the extract of the pheromone glands of the females. It was found that the main component (Z11-16Al) caused a well-pronounced 
reaction on the male antennae. It has been shown that the pheromone emitted by the females of the native population does not differ from the pheromone emitted by the females of the species Heliothis armigera, which lives in the geographical area of the Asian continent. The seasonal sexual cycle of the species Heliothis armigera was determined in the conditions of the natural habitat of the Republic of Moldova.

Key words: pheromone components, pheromonal traps, males, females, Heliothis armigera, seasonal monitoring.

\section{Introducere}

Este cunoscut faptul, că familia Noctuidae este una dintre cele mai mari familii din ordinul Lepidoptera. În fauna mondială sunt înregistrate aproximativ 25000 specii, în cea europeană - 1300, iar în fauna Republicii Moldova - 425 specii de noctuide. Diversitatea vastă a speciilor de noctuide pe teritoriul țării este determinată atât de variabilitatea biotopică, cât și de faptul aflării la interferența a trei regiuni biogeografice: Europeană - reprezentată de Podișul Central al Codrilor (54\%); Pontico-Centralasiatică - reprezentată de regiunile de silvostepă și stepă (30\%); Mediteraneană - căreia îi aparțin fragmente de silvostepă xerofite din partea de sud a republicii (16\%). Tot odată s-a constatat, că doar aproximativ 20 de specii formează lista dăunătorilor economic importanți pentru agricultura Republicii Moldova. Ecosistemele agricole ocupă circa $76 \%$ din teritoriu, iar diversitatea biologică a plantelor cultivate o constituie aproximativ 94 specii, care includ circa 553 soiuri și 50 hibrizi şi forme vegetale $[1 ; 2]$. Cele mai sus relatate au contribuit la faptul ca în ultimii ani specia Heliothis armigera să treacă în rândurile celor mai economic importanți dăunători a mai multor culturi agricole.

Datorită progresului vertiginos în domeniul chimiei feromonilor sexuali sintetici a devenit posibil de a aprecia eficienţa componenţilor, rolul lor în perioada comportamentului sexual, şi influența compoziţiilor fromonale asupra activităţii insectelor ţintă. Aprecierea corectă a ciclului de dezvoltare a speciilor de fitofagi are o importanţă majoră pentru aplicarea feromonilor sexuali în protecția plantelor. $\mathrm{Cu}$ cât eficienţa biologică a feromonilor sexuali de origine sintetică este mai aproape de eficienţa feromonilor sexuali emanaţi de către femele speciilor de fitofagi, cu atât mai precise şi efective sunt rezultatele obţinute în urma aplicări lor.

Scopul investigaţiilor în lucrarea dată a fost de a fi apreciată compoziţia optimală a feromonului sexual sintetic şi a determina ciclul sexual sezonier a speciei Heliothis armigera în condiţiile ecosistemelor agricole a Republicii Moldova.

\section{Materiale și metode}

Pentru obţinerea materialului biologic necesar, fitofagul dat a fost înmulţit în condiţii de laborator. Astfel au fost colectate 200 femele cu vârsta de 48 ore de la care apoi au fost preparate ultimele segmente abdominale pentru obţinerea extractului feromonal şi aprecierea numerică a componenţilor şi ratei lor în extractul obţinut. Componenţii feromonali obţinuţi, ulterior au fost testaţi la aparatul electroantenografic pentru aprecierea celor, care provoacă cea mai pronunţată reacţie asupra antenelor masculilor Heliothis armigera.

Pentru determinarea ciclului ontogenetic de dezvoltare sezonieră a populației Heliothis armigera au fost montate a câte 3 capcane feromonale la culturile cele mai preferabile - tomate, porumb zaharat, și soia. Analiza capcanelor s-a efectuat cu regularitate (o dată în 7 zile) pe întreagă perioadă de vegetație. Dispensatorii feromonali au fost înlocuiți o dată în 10-15 zile. Suporturile adezive au fost schimbate după necesitate. Rezultatele obținute au fost analizate în conformitate cu pachetul software Microsoft. 


\section{Rezultate și discuții}

Extractul feromonal obținut din ultimele segmente abdominale a femelelor de una și aceiași vârstă (48 ore) a fost supus divizării în componenți separați în laboratorul de chimie a substanțelor biologic active. Au fost obținuți și identificați 15 componenți feromonali, care ulterior au fost testați la aparatul electroantenografic pentru aprecierea reacției antenelor masculilor și comparate cu reacția la extractul din glandele feromonale în calitate de standard. Rezultatele obţinute sunt oglindite în tabelul 1.

Tabelul 1. Estimarea reacţiei antenelor masculilor Heliothis armigera prin intermediul aparatului electroantenografic, la componenţii obţinuți din extractul glandelor feromonale al femelelor

$($ Concentraţia componenţilor feromonali $=10 \mathrm{mkg}$; Sensibilitatea oscilografului $=50 ; \mathrm{n}=15)$

\begin{tabular}{|c|c|c|c|c|}
\hline nr. & Varianta & $\begin{array}{c}\text { Amplituda } \\
\text { medie } \\
(\mathrm{mV} \times 100)\end{array}$ & $\begin{array}{c}\text { Diferenţa } \\
\text { în comparaţie } \\
\text { cu St. }\end{array}$ & Grupul \\
\hline 1 & Extract (St.) & 271,2 & - & - \\
\hline 2 & Z9 - 16OH & 94,4 & $-176,8$ & III \\
\hline 3 & $\mathrm{Z11}-16 \mathrm{OH}$ & 103,2 & $-168,0$ & III \\
\hline 4 & Z11-16Ac & 87,1 & $-184,1$ & III \\
\hline 5 & $\mathrm{Z} 11-16 \mathrm{Al}$ & 267,9 & $-3,3$ & II \\
\hline 6 & $\mathrm{Z} 11-14 \mathrm{Al}$ & 101,0 & $-170,2$ & III \\
\hline 7 & E11-16Ac & 96,7 & $-174,5$ & III \\
\hline 8 & $\mathrm{H}-16 \mathrm{Al}$ & 131,0 & $-140,2$ & III \\
\hline 9 & Z11-14Ac & 100,0 & $-171,2$ & III \\
\hline 10 & E11 - 14Ac & 102,1 & $-169,1$ & III \\
\hline 11 & $\mathrm{Z11}-14 \mathrm{OH}$ & 97,8 & $-173,4$ & III \\
\hline 12 & $\mathrm{Z9}-14 \mathrm{OH}$ & 154,4 & $-116,8$ & III \\
\hline 13 & Z9-14Ac & 155,6 & $-115,6$ & III \\
\hline 14 & $\mathrm{Z9}-16 \mathrm{Al}$ & 165,4 & $-105,6$ & III \\
\hline 15 & $\mathrm{Z9}-14 \mathrm{Al}$ & 142,8 & $-128,4$ & III \\
\hline 16 & Z9-16Ac & 82,4 & $-188,8$ & III \\
\hline \multicolumn{5}{|c|}{ DEM $_{0,05}=12,4$} \\
\hline
\end{tabular}

Reieșind din rezultatele obţinute s-a constatat, că doar componentul principal, extras din glandele feromonale a femelelor $(\mathrm{Z} 11$ - 16Al), a provocat o reacţie, bine pronunțată, asupra antenelor masculilor, asemănătoare cu cea provocată de către extractul din glandele feromonale ale femelelor. Componenţii minori testaţi, nu au provocat o reacţie semnificativă asupra antenelor masculilor.

Ulterior, a fost estimată reacţia antenelor masculilor, provocată de către componenţii feromonali extraşi din glandele feromonale ale femelelor, în comparaţie cu compoziţia feromonului sexual sintetic standard, care se aplică cu succes în ţările de pe continentul Asiatic (regiunile cultivării pe suprafeţe enorme a culturii de bumbac). Analiza rezultatelor obţinute a demonstrat, că reacţia antenelor masculilor, provocată de către componentul principal al feromonului sexual (Z11 - 16Al), nu se deosebeşte esenţial în comparaţie cu reacţia antenelor masculilor, provocată de către compoziţia feromonului sexual sintetic existent - Z11-16Al (97\%) + Z9-16Al (3\%). Ceilalți componenţi minori, extrași din glandele feromonale ale femelelor, nu au provocat o reacţie mai esenţială asupra antenelor masculilor. Astfel testările efectuate au demonstrat, că compoziţia feromonului sexual emanat de către 
femelele populaţiei autohtone nu se deosebeşte esenţial după reacţia provocată masculilor, faţă de feromonul sexual emanat de către femelele populaţiilor speciei fitofagului $H$. armigera, care habitează în zona geografică a continentului Asiatic.

Reieșind din rezultatele testărilor componenţilor feromonali, extrași din glandele feromonale ale femelelor, sau elaborat și testat în condiții de câmp 8 compoziţii feromonale. Estimările reacţiei sexuale a masculilor Heliothis armigera din populația autohtonă, manifestată în condiții de câmp faţă de capcanele înzestrate cu compoziţiile feromonale elaborate sunt oglindite în tabelul 2.

Tabelul 2. Estimarea reacţiei masculilor Heliothis armigera din populația autohtonă în dependență de compoziţiile feromonale aplicate în capcane.

\begin{tabular}{|c|c|c|c|c|c|}
\hline Varianta & $\begin{array}{l}\text { Compoziţia } \\
\text { momelilor } \\
\text { feromonale }\end{array}$ & $\begin{array}{c}\text { Raportul } \\
\text { procentual al } \\
\text { componenţilor } \\
(\%)\end{array}$ & $\begin{array}{c}\text { Masculi } \\
\text { capturaţi } \\
\text { la o capcană }\end{array}$ & $\begin{array}{l}\text { Devierea } \\
\text { de la St. }\end{array}$ & Grupul \\
\hline \multirow{2}{*}{ I (St.) } & $\mathrm{Z} 11-16 \mathrm{Al}$ & 97 & \multirow{2}{*}{135,7} & \multirow[b]{2}{*}{-} & \multirow[b]{2}{*}{ - } \\
\hline & $\mathrm{Z} 9-16 \mathrm{Al}$ & 3 & & & \\
\hline \multirow{2}{*}{ II } & $\mathrm{Z} 11-16 \mathrm{Al}$ & 95 & \multirow{2}{*}{98,3} & \multirow{2}{*}{$-37,4$} & \multirow{2}{*}{ II } \\
\hline & $\mathrm{Z9}-16 \mathrm{Al}$ & 5 & & & \\
\hline \multirow{2}{*}{ III } & $\mathrm{Z} 11-16 \mathrm{Al}$ & 90 & \multirow{2}{*}{106,3} & \multirow{2}{*}{$-29,4$} & \multirow{2}{*}{ II } \\
\hline & $\mathrm{Z9}-16 \mathrm{Al}$ & 10 & & & \\
\hline \multirow{3}{*}{ IV } & $\mathrm{Z} 11-16 \mathrm{Al}$ & 90 & \multirow{3}{*}{39,7} & \multirow{3}{*}{$-96,0$} & \multirow{3}{*}{ III } \\
\hline & $\mathrm{Z9}-16 \mathrm{Al}$ & 5 & & & \\
\hline & $\mathrm{Z9}-14 \mathrm{Al}$ & 5 & & & \\
\hline \multirow{3}{*}{ V } & $\mathrm{Z} 11-16 \mathrm{Al}$ & 95 & \multirow{3}{*}{96,0} & \multirow{3}{*}{$-39,7$} & \multirow{3}{*}{ II } \\
\hline & $\mathrm{Z9}-16 \mathrm{Al}$ & 4 & & & \\
\hline & $\mathrm{H}-16 \mathrm{Al}$ & 1 & & & \\
\hline \multirow{3}{*}{ VI } & $\mathrm{Z} 11-16 \mathrm{Al}$ & 90 & \multirow{3}{*}{96,7} & \multirow{3}{*}{$-39,0$} & \multirow{3}{*}{ II } \\
\hline & $\mathrm{Z9}-16 \mathrm{Al}$ & 8 & & & \\
\hline & $\mathrm{H}-16 \mathrm{Al}$ & 2 & & & \\
\hline \multirow{3}{*}{ VII } & $\mathrm{Z} 11-16 \mathrm{Al}$ & 80 & \multirow{3}{*}{140,3} & \multirow{3}{*}{$+4,6$} & \multirow{3}{*}{ II } \\
\hline & $\mathrm{Z} 9-16 \mathrm{Al}$ & 16 & & & \\
\hline & $\mathrm{H}-16 \mathrm{Al}$ & 4 & & & \\
\hline \multirow{4}{*}{ VIII } & $\mathrm{Z} 11-16 \mathrm{Al}$ & 87 & \multirow{4}{*}{107,7} & \multirow{4}{*}{$-28,0$} & \multirow{4}{*}{ II } \\
\hline & $\mathrm{Z9}-16 \mathrm{Al}$ & 3 & & & \\
\hline & $\mathrm{Z7}-16 \mathrm{Al}$ & 2 & & & \\
\hline & $\mathrm{H}-16 \mathrm{Al}$ & 8 & & & \\
\hline
\end{tabular}

Analiza rezultatelor obţinute a demonstrat, că între compoziţiile feromonale testate (în afară de varianta IV), nu au fost fixate oarecare deosebiri semnificative în ce priveşte reacţia manifestată de către masculi la capcanele înzestrate cu momelele corespunzătoare. Reieșind din cele expuse confirmăm, că cea mai optimală reacţie, masculii Heliothis armigera o manifestă faţă de compoziţia feromonală - Z11-16Al (97\%) + Z9-16Al (3\%). Astfel a fost demonstrat şi în condiţiile de câmp, că compoziţia feromonului sexual sintetic existent pentru specia dată, este caracteristic şi pentru populaţia autohtonă a speciei Heliothis armigera. 
Metoda de obținere a componentului principal al feromonului sexual al buhei Heliothis armigera (cis-11-hexadecenal) a fost elaborată în baza unei scheme modificate de sinteză.

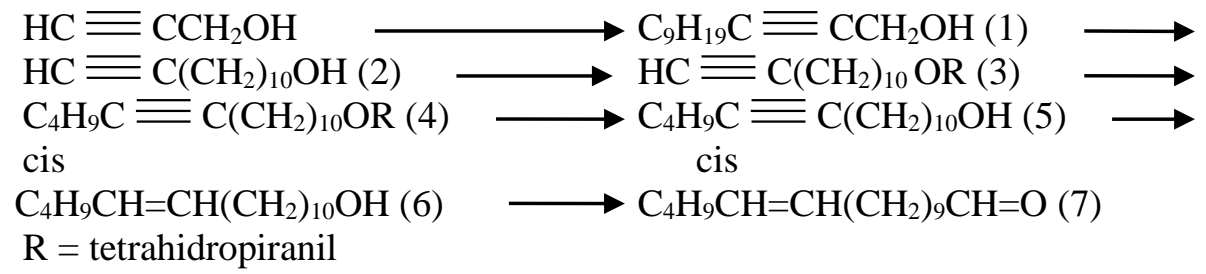

Datorită aplicării schemei modificate de sinteză, costul feromonului corespunzător s-a redus cu circa $50 \%$ comparativ cu costul feromonului sintetizat după schema Standard. În rezultatul evaluării comparative a activităţii compoziţiei feromonale standarde cu adăugarea componentului tocoferol (în calitate de antioxidant) - «Z11 - 16Al (97\%) + Z9 - 16Al (3\%) + [(2R-2,5,7,8-tetramethyl-2-(4R,8R)-4,8,12-trimethyltridecy-3,4-dihydro-2H-chromen-6-ol]» $\mathrm{s}$-a constatat o majorare a atractivității în timp și număr a masculilor.

Cunoaşterea ciclului activităţii sexuale sezoniere a speciilor de fitofagi, favorizează cu mult aplicarea mijloacelor de reglare a densităţii populaţiilor lor. Analiza rezultatelor obţinute a demonstrat, că specia Heliothis armigera se dezvoltă în condiţiile agroclimaterice a Republicii Moldova în trei generaţii. Pe parcursul investigaţiilor a fost fixat, că în prima generaţie masculii sunt sexual activi în limita decadei II a lunii mai şi decadei III a lunii iunie. Intervalul între prima generaţie şi a doua este bine evidenţiat. Activitatea sexuală a masculilor generaţiei a doua a fost fixată începând cu a doua jumătate a lunii iulie. Intervalul între generaţiile a doua şi a treia este complicat de a fi evidenţiat, deoarece reacţia sexuală a masculilor unei generaţii, manifestată faţă de capcanele feromonale, se suprapun cu activitatea sexuală a masculilor din altă generaţie. Din aceste considerente a fost apreciat, că activitatea sexuală a masculilor generaţiei a treia se extinde până la finele lunii septembrie (figura 1).

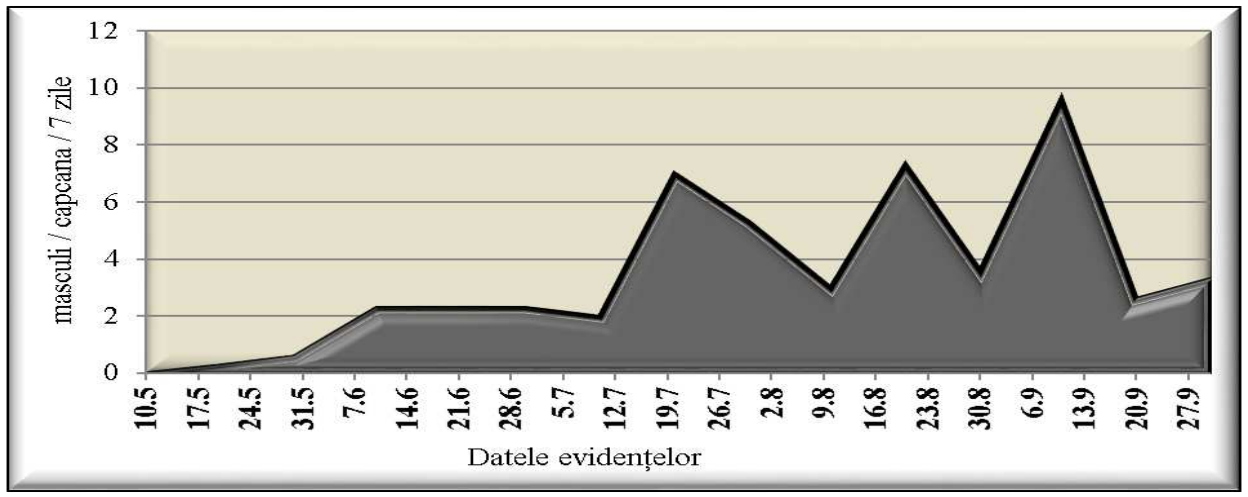

Figura 1. Ciclului sexual sezonier a speciei Heliothis armigera în condiţile habitatului natural a Republicii Moldova.

Astfel, prin intermediul capcanelor feromonale a fost apreciat ciclul activităţii sexuale sezoniere a masculilor speciei Heliothis armigera în condiţiile agroclimaterice a Republicii Moldova. A fost demonstrată perioada în care specia dată provoacă cele mai mari daune culturilor agricole. Rezultatele obţinute pot servi ca bază în aplicarea diferitor mijloace de reducere a densităţii populaţiei speciei date până la nivelul pragului economic de daună. 


\section{Concluzii}

A fost estimată reacţia antenelor masculilor Heliothis armigera prin intermediul aparatului electroantenografic, la componenţii obţinut din extractul glandelor feromonale al femelelor. S-a constatat, că componentul principal (Z11-16Al), a provocat o reacţie, bine pronunțată, asupra antenelor masculilor;

S-a demonstrat, că feromonul emanat de către femelele populaţiei autohtone nu se deosebeşte de feromonul emanat de către femelele speciei Heliothis armigera, care habitează în zona geografică a continentului Asiatic;

A fost determinat ciclul sexual sezonier a speciei Heliothis armigera în condiţiile habitatului natural a Republicii Moldova (prima generaţie - masculii sunt activi în limitele decadei II a lunii mai și decadei III a lunii iunie; generaţia a doua - începând cu a doua jumătate a lunii iulie; generaţia a treia - se extinde până la finele lunii septembrie).

\section{Bibliografie}

1. ȚUGULEA, C., Specii din genul Euxoa Hubner, 1821 (Lepidoptera, Noctuidae) - noi pentru fauna Republicii Moldova. In Buletinul Academiei de Științe a Moldovei. Științele Vieții. 2019, nr. 1 (337), pp. 121-124. ISBN 1857-064X. 60.

2. ȚUGULEA, C., DERJANSCHI, V. Istoricul studiul noctuidelor (Lepidoptera, Noctuidae) în Republica Moldova. In Buletin Științific. Revistă de Etnografie, Științele Naturii și Muzeologie. Serie nouă. Fascicula Științele Naturii. Chișinău, 2015, nr.22 (35), pp.59-81 ISSN 1857-0054. 